\title{
Global comparison of gene expression between subcutaneous and intramuscular adipose tissue of mature Erhualian pig
}

\author{
W.X. Sun ${ }^{1}$, H.H. Wang ${ }^{1,2}$, B.C. Jiang ${ }^{1}$, Y.Y. Zhao ${ }^{1}$, Z.R. Xie ${ }^{1}$, K. Xiong ${ }^{1}$ \\ and J. Chen ${ }^{1}$ \\ ${ }^{1}$ College of Animal Science and Technology, Nanjing Agricultural University, \\ Nanjing, Jiangsu, China \\ ${ }^{2}$ Hangzhou Academy of Agricultural Sciences, Hangzhou, Zhejiang, China \\ Corresponding author: J. Chen \\ Email: jiechen@njau.edu.cn
}

Genet. Mol. Res. 12 (4): 5085-5101 (2013)

Received March 20, 2013

Accepted September 18, 2013

Published October 29, 2013

DOI http://dx.doi.org/10.4238/2013.October.29.3

\begin{abstract}
Adipose tissue plays an important role in energy metabolism and related diseases. The content of intramuscular fat significantly influences the pork quality. In this study, the whole gene expression of dorsal subcutaneous (s.c.) adipose tissue and intramuscular (i.m.) adipose tissue isolated from longissimus dorsi muscle tissue were compared using Affymetrix Gene-Chip microarray technology. The result revealed that 1228 genes were more highly expressed in s.c. adipose tissue, whereas 965 genes were higher expressed in i.m. adipose tissue. We found that the s.c. adipose tissue had a stronger capacity of lipid metabolism and fatty acid metabolism compared with i.m. adipose tissue, and angiopoietinlike-4, neuronatin, neuron-derived orphan receptor-1 alfa, and chloride intracellular channel 5 may play important roles in the regulation of fat deposition between i.m. and s.c. adipose tissues.
\end{abstract}

Key words: Subcutaneous adipose tissue; Intramuscular adipose tissue; Lipid metabolism; Fatty acid metabolism 


\section{INTRODUCTION}

In livestock production, the content of intramuscular fat (IMF) plays an important role in the sensory quality of pork and is implicated in consumer acceptance (Fernandez et al., 1999; Webb and O'Neill, 2008). The aim of modern pig breeding is to produce lean meat with a reasonable IMF content. However, it is well documented that IMF content has decreased significantly as a result of long-term intensive selection for increased leanness and thin back fat (Hermesch et al., 2000). A decrease in back fat will lead to a reduction in IMF content, since there is a moderate positive correlation between IMF content and back fat thickness (Lo et al., 1992; Suzuki et al., 2005). This correlation is unfavorable, but reasonable, since both subcutaneous (s.c.) and intramuscular (i.m.) adipocytes share the same regulatory process of adipogenesis. Therefore, to produce lean pork with a reasonable IMF content remains a challenge for modern pig breeding research.

The profiles of adipocyte differentiation and metabolism might be different according to their locations. The difference of various adipose depots, such as s.c., i.m., visceral, and perirenal adipose tissue, has been compared in humans (Vohl et al., 2004) and cows (Pickworth et al., 2011). The growth and differentiation of adipocytes are different between fat and muscle tissues (Sun et al., 2004; Hausman and Hausman, 2006). Intramuscular adipocytes different from those in other depots because that they are distributed among muscle fibers. The IMF content might be influenced by muscle fiber. Adipocyte membrane interactions with the extracellular matrix and with neighboring myofibroblast might trigger a variety of responses within the adipocytes (Katz et al., 2000). Intramuscular adipogenesis can be specifically inhibited by myostatin, which is a muscle-specific secreted peptide (Rebbapragada et al., 2003). However, the whole gene comparison between i.m. and s.c. adipose tissues in mature pigs has not been done in vivo. The in vitro culture system might have erased such important signal responses, whereas the in vivo experiment can reflect the physiological process of the organism.

In this study, we conducted a transcriptional comparison between i.m. and s.c. adipose tissues using mature Erhualian pigs in order to investigate the molecular differences between the two fat tissues. The results can facilitate deeper insight into the specific regulatory mechanisms of i.m. adipogenesis.

\section{MATERIAL AND METHODS}

\section{Tissue samples}

Male Erhualian pigs at 7 months of age and about $60 \mathrm{~kg}$ were used in this experiment. The pigs were from Erhualian protected areas in Chang Zhou City, China. All procedures of the experiments were done according to "The Instructive Notions with Respect to Caring for Laboratory Animals", enacted by the Ministry of Science and Technology of the People's Republic of China. The pigs were exsanguinated after electric stunning. Dorsal s.c. adipose tissue and longissimus dorsi (LD) muscle tissue were separated immediately from the junction of the thoracic and lumbar vertebrae after sabotage, and stored in liquid nitrogen until RNA extraction and i.m. adipose tissue segregation. The i.m. adipose tissue was carefully segregated using ophthalmology tweezers and scalpels to avoid muscle fibers contamination. The isolation was completed on ice in $5 \mathrm{~min}$ in order to decrease the RNA degradation. 


\section{RNA isolation}

Total RNA was extracted from the s.c. and i.m. adipose tissues using Trizol reagent (Invitrogen, Carlsbad, USA), according to the manufacturer description. The absorbance values at 260 and $280 \mathrm{~nm}$ were checked to assess the RNA concentration and purity using the NanoDrop1000 Spectrophotometer (Thermo, USA). The $\mathrm{A}_{260} / \mathrm{A}_{280}$ ratio was evaluated for protein impurities in the samples. The RNA integrity was checked by electrophoresis on $2 \%$ agarose gels $(\mathrm{m} / \mathrm{v})$.

\section{Microarray assay}

The gene chip of the Porcine Genome Array (Affymetrix, Santa Clara, USA), which includes 23,937 probes, containing 23,256 transcripts of 20,201 Sus scrofa genes, was used in the experiments. The total RNAs of s.c. and i.m. adipose tissues were individually hybridized with gene chips. Briefly, in the first-strand cDNA synthesis reaction, $10 \mathrm{mg}$ total RNA was used for reverse transcription using a T7-oligo(dT) promoter primer. Then, the doublestranded cDNA was synthesized from the first-strand cDNA using Rnase H. After purification of the resulting DNA, an in vitro transcription reaction was done to produce biotin-labeled cRNA using the MEGA Script T7 Kit (Ambion, Inc., USA). After the biotin-labeled cRNA had been cleaned up and fragmented, the cRNA was hybridized to the probe array at $45^{\circ} \mathrm{C}$ for $16 \mathrm{~h}$. Thereafter, the probe array was washed and stained on the fluidics station, and the microarrays were scanned using the GeneChip Scanner 3000 (Affymetrix). The Affymetrix Micro Array Suite 5.0-Specific Terms GCOS version 1.4 was used for the quantity analysis of the hybridization. The gene expression levels that had $\geq 2$-fold difference between s.c. and i.m. adipose tissues were checked and further analyzed. The microarray assay was carried out by Capital Bio Corporation. The Molecule Annotation System (http://bioinfo.capitalbio.com/ mas) was used to analyze the differentially expressed genes, using the Kyoto encyclopedia of genes and genomes (KEGG) public pathway resource and gene ontology (GO) consortium.

\section{Real-time reverse transcription-polymerase chain reaction (RT-PCR)}

RT-PCR was performed to confirm the microarray results. Total RNA was extracted from s.c. and i.m. adipose tissues as described above and total RNA was reverse transcribed using a revere transcription kit (TaKaRa, Dalian, China) according to the manufacturer protocols. The expression levels were checked for 13 genes: fatty acid synthase (FAS), leptin (LEP), adiponectin (ADIPOQ), peroxisome proliferator-activated receptor gamma (PPAR- $\gamma$ ), fatty acid-binding protein 5 (FABP5), fatty acid-binding protein 4, adipocyte (FABP4), lipoprotein lipase (LPL), glucose phosphate isomerase (GPI), cyclin D2 (CCND2), insulin-like growth factor 2 (IGF2), neuron-derived orphan receptor-1 alfa (NOR-1 $\alpha$ ), triosephosphate isomerase 1 (TPI1), and transducer of ERBB2, 1 (TOB1). The $\beta$-actin gene (ATCB) was used as the invariant control. Primers were designed using Primer Premier 5.0 and are shown in Table 1. RT-PCR was performed using the Fast Start Universal SYBR Green Master (Ta$\mathrm{KaRa}$ ) with a $20-\mu \mathrm{L}$ reaction system, according to the manufacturer protocol, in an ABI 7300 instrument. The thermal conditions of RT-PCR were as follows: $95^{\circ} \mathrm{C}$ for $30 \mathrm{~s}$, followed by 40 cycles of degenerating at $95^{\circ} \mathrm{C}$ for $5 \mathrm{~s}$, and annealing and extension at $60^{\circ} \mathrm{C}$ for $1 \mathrm{~min}$. The melting-curve analysis was performed in order to monitor the specificity of production. All 
experiments were repeated three times. The gene expression levels in the s.c. and i.m. adipose tissues were analyzed with the $2^{-\Delta \Delta C \mathrm{CT}}$ method.

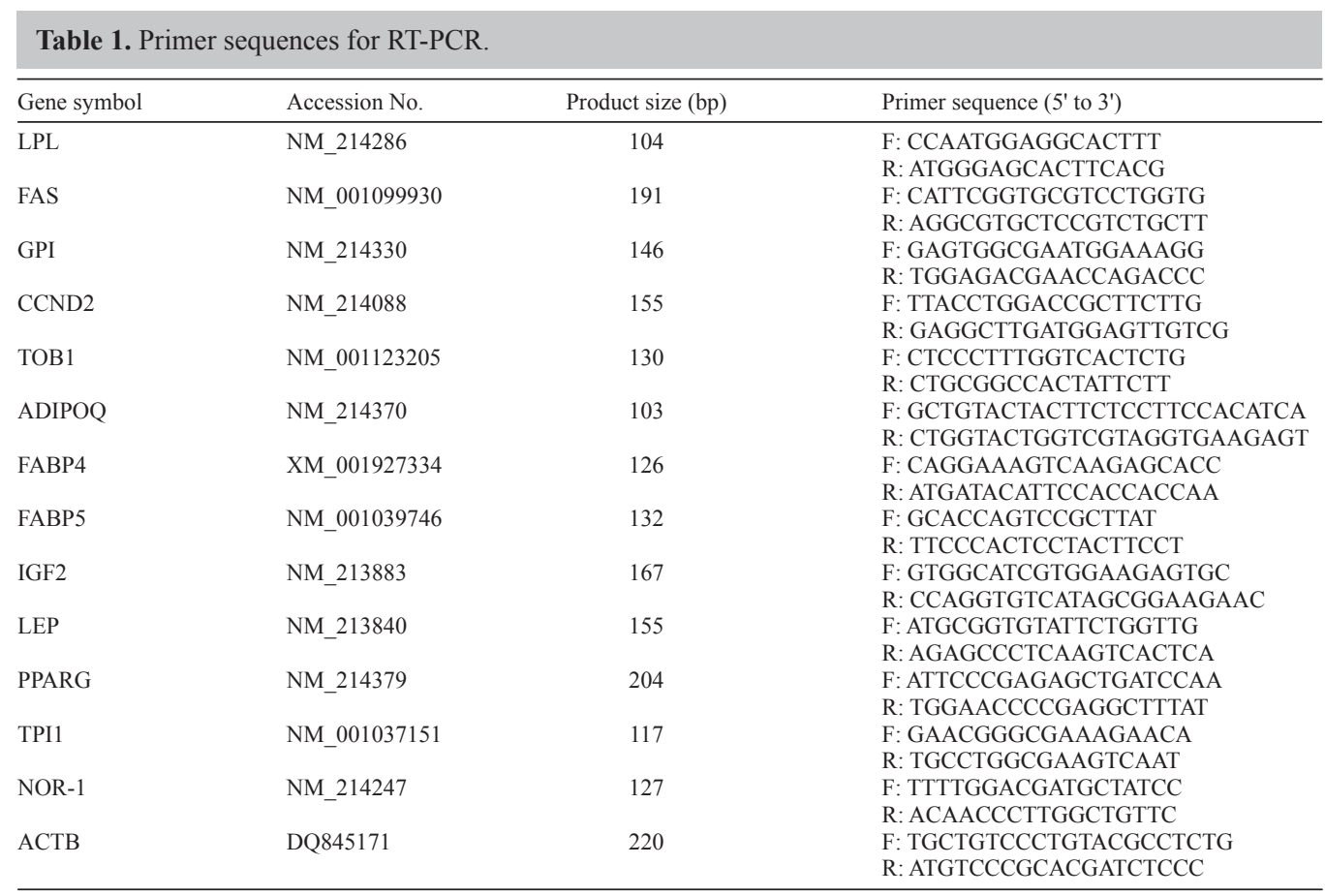

\section{Statistical analysis}

Data are reported as means \pm SE. Differences of mRNA expression levels were analyzed by the independent-samples $t$-test (SPSS Inc., Chicago, IL, USA). P $<0.05$ was considered statistically significant.

\section{RESULTS}

\section{Differentially expressed genes}

After quantifying all hybridization spots, the signal intensity was plotted logarithmically. Figure 1 shows the scatter plot of microarray signals of s.c. and i.m. adipose tissues. It shows that the expression levels of many genes were different between the two samples. According to the statistics, $60.08 \%(14,493 / 24,123)$ probes were checked out in the s.c. adipose tissue sample, and $65.44 \%(15,787 / 24,123)$ gene probes were inspected in the i.m. adipose tissue sample. The comparison of the two samples revealed that 1281 probes, representing 1228 transcripts, including 234 known genes (Table 2), were up-regulated ( $\geq 2$ folds) in s.c. adipose tissue, whereas 1076 probes, representing 965 transcripts, including 172 recognized genes (Table 3), were up-regulated in i.m. adipose tissue ( $\geq 2$ folds). 


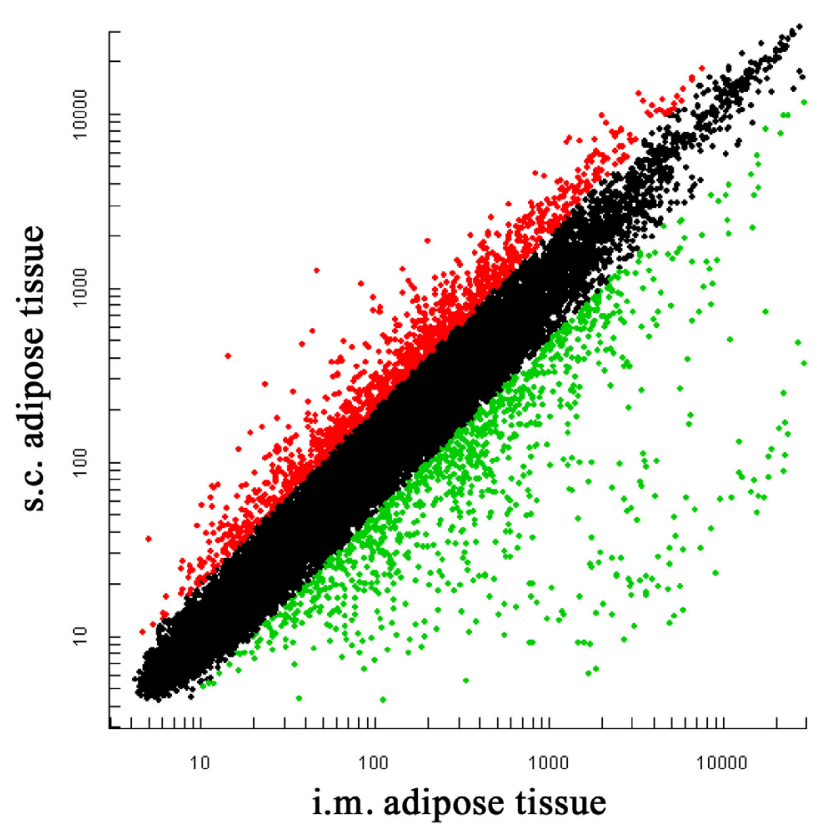

Figure 1. Log-Log Scatter Plot of subcutaneous (s.c.) and intramuscular (i.m.) adipose tiusse. Red replaces higher expressed genes in s.c adipose tissue. Green replaces the higher expressed genes in i.m adipose tissue.

\section{Results of GO and KEGG analyses}

In order to clarify the different biological patterns of the two samples, significantly different genes in the s.c. and i.m. adipose samples were individually analyzed by GO and KEGG of the criterion $\mathrm{P}<0.05$.

The GO results (Table 4) showed that of the highly expressed genes in the s.c. sample, $49.25 \%$ were for biological processes, $35.15 \%$ for molecular function, $14.10 \%$ for cellular components, and $1.504 \%$ for other items; correspondingly, $49.16 \%$ were for biological processes, $31.76 \%$ for molecular function, $18.17 \%$ for cellular components, and $1.014 \%$ for other items in the i.m. sample. With regards the biological processes, the highly expressed genes in the s.c. adipose sample (Figure 2A) significantly belonged to fatty acid $\beta$-oxidation, fatty acid metabolism, lipid metabolism, and fatty acid oxidation. Corresponding, the highly expressed genes in the i.m. adipose sample (Figure 2B) were mainly implicated in negative regulation of fat cell differentiation, DNA methylation, glycolysis, and positive regulation of histone acetylation.

The genes that were significantly expressed in the s.c. and i.m. samples were analyzed in KEGG (Figure 3). Figure 3A shows that the highly expressed genes in s.c. fat belong to glycolysis/ gluconeogenesis, fatty acid metabolism, fatty acid elongation in mitochondria, glycerolipid metabolism, adipocytokine signaling pathway, Janus kinase/signal transducer and activator of transcription signaling pathway, and insulin signaling pathway. The highly expressed genes in i.m. fat were involved in the mitogen-activated protein kinase cascades signaling pathway, Wingless and INT-1 signaling pathway, adipocytokine signaling pathway, cell communication, cell cycle, insulin signaling pathway, and transforming growth factor- $\beta$ signaling pathway (Figure 3B). 
Table 2. Highly expressed genes in subcutaneous adipose tissue.

\begin{tabular}{|c|c|c|c|}
\hline Gene title & Gene symbol & Representative public ID & Ratio \\
\hline Retinol binding protein 7 & RBP7 & CN155390 & 27.037 \\
\hline Lysozyme & LYZ & NM_214392.1 & 12.564 \\
\hline Steroidogenic acute regulatory protein & STAR & NM_213755.1 & 12.445 \\
\hline Guanylate binding protein 1 & GBP1 & CO950381 & 9.214 \\
\hline Phosphoenolpyruvate carboxykinase 1 & $\mathrm{CH} 242-37 \mathrm{G} 9.2$ & BX676168 & 9.069 \\
\hline Secretogranin V & SCG5 & M23654.1 & 7.572 \\
\hline Amelogenin & AMELX & NM_213906.1 & 7.162 \\
\hline Interleukin 15 & IL15 & NM_214390.1 & 6.873 \\
\hline Regulator of G-protein signaling 1 & RGS1 & AF139837.1 & 6.562 \\
\hline Adipose differentiation-related protein & ADRP & AY550037.1 & 6.416 \\
\hline Kallikrein & KLKB1 & NM_214074.1 & 5.951 \\
\hline C-type lectin domain family 5 , member A & CLEC5A & NM_213990.1 & 5.523 \\
\hline Aquaporin 3 & AQP3 & CK 451710 & 5.445 \\
\hline Secretory leukocyte peptidase inhibitor & SLPI & NM_213870.1 & 5.438 \\
\hline Microseminoprotein, beta & MSMB & NM_213852.1 & 5.113 \\
\hline Apolipoprotein E & APOE & NM_214308.1 & 4.818 \\
\hline $\begin{array}{l}\text { Sulfotransferase family, cytosolic, } \\
2 \mathrm{~A} \text {, dehydroepiandrosterone-preferring, member } 1\end{array}$ & SULT2A1 & BI402591 & 4.796 \\
\hline Aldo-keto reductase family 1 , member $\mathrm{C} 4$ & AKR1C4 & BI184598 & 4.743 \\
\hline Porcine inhibitor of carbonic anhydrase & PICA & NM_213847.1 & 4.733 \\
\hline Ficolin & LOC396881 & NM_213868.1 & 4.717 \\
\hline Carboxylesterase & CES3 & NM_214246.1 & 4.674 \\
\hline Lipoprotein lipase & LPL & AY686760.1 & 4.652 \\
\hline Glycerol kinase & GK & CK457408 & 4.63 \\
\hline Ameloblastin & AMBN & NM_214037.1 & 4.601 \\
\hline CD86 molecule & CD86 & NM_214222.1 & 4.437 \\
\hline Adiponectin, C1Q, and collagen domain containing & ADIPOQ & AY589691.1 & 4.417 \\
\hline Angiopoietin-like 4 & ANGPTL4 & BI183736 & 4.393 \\
\hline Acyl-Coenzyme A dehydrogenase, long chain & ACADL & NM_213897.1 & 4.374 \\
\hline Glycoprotein nmb & GPNMB & CN153410 & 4.29 \\
\hline Ras homolog gene family, member $\mathrm{F}$ & RHOF & CK455476 & 4.079 \\
\hline Fructose 1,6-bisphosphatase & FBP & NM_213979.1 & 4.054 \\
\hline Microsomal glutathione S-transferase 1 & MGST1 & NM_214300.1 & 4.023 \\
\hline Peptidoglycan recognition protein $\mathrm{L}$ & pPGRP-LB & NM_213738.1 & 3.911 \\
\hline Occludin & OCLN & CF368080 & 3.844 \\
\hline Chemokine ligand 2 & CCL2 & NM_214214.1 & 3.831 \\
\hline Growth hormone receptor & GHR & 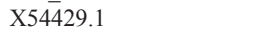 & 3.828 \\
\hline Phospholipase A2, group VII & PLA2G7 & BQ603958 & 3.815 \\
\hline Insulin induced gene 1 & INSIG1 & BP454285 & 3.714 \\
\hline Vascular endotheial growth factor 2 & LOC414908 & BI360137 & 3.635 \\
\hline Paraoxonase 3 & PON3 & BX667193 & 3.583 \\
\hline CD247 molecule & CD247 & CF367898 & 3.558 \\
\hline MyoD family inhibitor domain containing & MDFIC & BF075680 & 3.531 \\
\hline Secreted phosphoprotein 1 & SPP1 & NM_214023.1 & 3.529 \\
\hline Aquaporin 11 & LOC100127151 & CN070334 & 3.51 \\
\hline GTP binding protein overexpressed in skeletal muscle & GEM & Z80109.1 & 3.478 \\
\hline Malic enzyme 1, NADP(+)-dependent, cytosolic & ME1 & CN163851 & 3.461 \\
\hline 3-beta-hydroxysteroid dehydrogenase/delta-5-delta-4 isomerase & 3B-HSD & CO946466 & 3.46 \\
\hline Prostaglandin reductase 1 & PTGR1 & NM_214385.1 & 3.446 \\
\hline Phosphogluconate dehydrogenase & PGD & CN159092 & 3.413 \\
\hline Monoglyceride lipase & MGLL & CN028971 & 3.387 \\
\hline Fatty acid synthase & FAS & CF180911 & 3.354 \\
\hline Methylmalonyl CoA epimerase & MCEE & CN166359 & 3.343 \\
\hline $\begin{array}{l}\text { Guanine nucleotide binding protein, } \\
\text { alpha inhibiting activity polypeptide } 1\end{array}$ & GNAI1 & U11249.1 & 3.343 \\
\hline Enoyl Coenzyme A hydratase 1, peroxisomal & ECH1 & BI183989 & 3.321 \\
\hline Fatty acid binding protein 7 , brain & FABP7 & CK463743 & 3.273 \\
\hline Complement component C9 & LOC100037951 & CF362312 & 3.265 \\
\hline
\end{tabular}

Continued next on the page 
Table 2. Continued.

\begin{tabular}{|c|c|c|c|}
\hline Gene title & Gene symbol & Representative public ID & Ratio \\
\hline Lipase, hormone-sensitive & LIPE & AY686758.1 & 3.24 \\
\hline Adiponectin receptor 2 & ADIPOR2 & CN156813 & 3.215 \\
\hline MHC class II DR-alpha & SLA-DRA & AY285933.1 & 3.212 \\
\hline Ubiquitin carboxyl-terminal esterase L1 & UCHL1 & CO947028 & 3.199 \\
\hline Glutathione peroxidase 3 & GPX3 & BX671405 & 3.194 \\
\hline Protein phosphatase 1 catalytic subunit alpha isoform & LOC733611 & BP157767 & 3.183 \\
\hline Microsomal glutathione S-transferase 3 & MGST3 & CK466828 & 3.18 \\
\hline Flavin containing monooxygenase 1 & FMO1 & NM_214064.1 & 3.175 \\
\hline 3-oxoacid CoA transferase 1 & OXCT1 & NM_213938.1 & 3.151 \\
\hline Transketolase & TKT & CN163555 & 3.142 \\
\hline Dehydrogenase/reductase member 4 & DHRS4 & NM_214019.1 & 3.139 \\
\hline Chemokine ligand 4 & CCL4 & NM_213779.1 & 3.134 \\
\hline Protein phosphatase 2 , regulatory subunit $\mathrm{A}$, beta isoform & PPP2R1B & CN160205 & 3.122 \\
\hline Carboxylesterase 1 & CES1 & CF365558 & 3.055 \\
\hline Feline leukemia virus subgroup C cellular receptor family, member 2 & FLVCR2 & CF177239 & 3.053 \\
\hline Topoisomersae II & TOPOII & NM_213884.1 & 3.027 \\
\hline 1-acylglycerol-3-phosphate O-acyltransferase 1 & SBAB-649D6.6 & BG608754 & 3.025 \\
\hline ADP-ribosylation factor-like protein 4A & LOC595121 & BF194181 & 3.024 \\
\hline Chemokine receptor 4 & CXCR4 & NM_213773.1 & 2.977 \\
\hline Cell death-inducing DNA fragmentation factor-like effector a & LOC100127171 & $\mathrm{BX} 675760$ & 2.976 \\
\hline $\mathrm{NAD}(\mathrm{P}) \mathrm{H}$ dehydrogenase, quinone 1 & NQO1 & BQ601005 & 2.966 \\
\hline Ribosomal protein, large, P1 & RPLP1 & AY550065.1 & 2.954 \\
\hline Glutamyl aminopeptidase & ENPEP & NM_214017.1 & 2.939 \\
\hline Cytochrome b5 type B & CYB5B & $\mathrm{CN} 154133$ & 2.923 \\
\hline Peroxisome proliferator-activated receptor gamma & PPARG & AB097926.1 & 2.917 \\
\hline Lipase A & LIPA & CO986683 & 2.909 \\
\hline Cystatin B & CSTB & CN164516 & 2.908 \\
\hline Cytochrome P450, family 27 , subfamily A, polypeptide 1 & CYP27A1 & CN153890 & 2.9 \\
\hline Chemokine receptor 1 & CCR1 & NM_001001621.1 & 2.892 \\
\hline 2,4-dienoyl CoA reductase 1 & DECR1 & BQ602989 & 2.875 \\
\hline Renin binding protein & RENBP & D83766.1 & 2.857 \\
\hline Cytochrome b5 type A & CYB5A & NM_001001770.1 & 2.84 \\
\hline Lectin, galactoside-binding, soluble, 3 & LGALS3 & $\mathrm{BX} \overline{6} 76137$ & 2.837 \\
\hline PRA1 family protein-like protein & LOC595127 & CF793094 & 2.836 \\
\hline Adrenomedullin & $\mathrm{ADM}$ & NM_214107.1 & 2.819 \\
\hline $\mathrm{N}$-acetylneuraminate pyruvate lyase & NPL & NM_214071.1 & 2.811 \\
\hline Cystathionase & LOC733654 & CN165749 & 2.805 \\
\hline $\mathrm{G}$ protein-coupled receptor 120 & GPR120 & BI402064 & 2.781 \\
\hline Coagulation factor $\mathrm{V}$ & F5 & NM_214120.1 & 2.778 \\
\hline Translocator protein & TSPO & NM_213753.1 & 2.759 \\
\hline Killer cell lectin-like receptor subfamily K, member 1 & KLRK1 & NM_213813.1 & 2.758 \\
\hline v-myc myelocytomatosis viral oncogene homolog & MYC & NM_001005154.1 & 2.737 \\
\hline Solute carrier family 11 , member 1 & SLC11A1 & U55068.1 & 2.725 \\
\hline Cell division cycle $2, \mathrm{G} 1$ to $\mathrm{S}$ and $\mathrm{G} 2$ to $\mathrm{M}$ & $\mathrm{CDC} 2$ & AJ687786 & 2.725 \\
\hline Hypothetical & LOC100152232 & CF363286 & 2.724 \\
\hline Integral membrane protein & ITM2A & CK462331 & 2.722 \\
\hline Crystallin, zeta-like 1 & CRYZL1 & CN163225 & 2.718 \\
\hline Glutathione S-transferase omega & GSTO1 & NM_214050.1 & 2.712 \\
\hline MHC class I antigen 1 & SLA-1 & $\mathrm{AB} \overline{105382.1}$ & 2.707 \\
\hline NK-lysin & NKL & BX672894 & 2.707 \\
\hline Glutathione reductase & GSR & CK461867 & 2.695 \\
\hline Quinoid dihydropteridine reductase & QDPR & BM189976 & 2.694 \\
\hline Branched chain keto acid dehydrogenase E1, beta polypeptide & BCKDHB & CO943570 & 2.677 \\
\hline Karyopherin alpha 2 & KPNA2 & BG382957 & 2.656 \\
\hline Elastase, neutrophil expressed & ELANE & NM_214109.1 & 2.65 \\
\hline Cellular disintegrin precursor & ADAM-9 & AJ68 1165 & 2.638 \\
\hline CD1 antigen & CD1.1 & NM_213831.1 & 2.635 \\
\hline BTG family, member 3 & BTG3 & BQ600276 & 2.629 \\
\hline
\end{tabular}

Continued next on the page 
Table 2. Continued.

\begin{tabular}{|c|c|c|c|}
\hline Gene title & Gene symbol & Representative public ID & Ratio \\
\hline Haptocorrin & LOC396873 & BX675338 & 2.625 \\
\hline Laminin, beta 1 & LAMB1 & CN155839 & 2.605 \\
\hline GTP-binding protein SAR1a & LOC595115 & CK449626 & 2.58 \\
\hline POT1 protection of telomeres 1 homolog & POT1 & BF703953 & 2.578 \\
\hline Zona pellucida binding protein & ZPBP & NM_214106.1 & 2.571 \\
\hline MHC class II histocompatibility antigen SLA-DRB1 & SBAB-591C4.1 & $\mathrm{AB} 016750.1$ & 2.569 \\
\hline Paraoxonase 2 & PON2 & CO951896 & 2.556 \\
\hline Leptin & LEP & AF052691.1 & 2.55 \\
\hline Lymphocyte antigen 96 & LY96 & BX918583 & 2.546 \\
\hline Peroxiredoxin 5 & PRDX5 & NM_214144.1 & 2.542 \\
\hline Acyl-CoA synthetase short-chain family member 2 & ACSS2 & AW483183 & 2.539 \\
\hline Phytanoyl-CoA 2-hydroxylase & PHYH & CB475937 & 2.526 \\
\hline Electron-transfer-flavoprotein, beta polypeptide & ETFB & CN158539 & 2.524 \\
\hline Tyrosine 3/5-monooxygenase activation protein, zeta polypeptide & YWHAZ & CN153545 & 2.507 \\
\hline Acyl-Coenzyme A oxidase 1, palmitoyl & ACOX1 & BP447334 & 2.504 \\
\hline Long-chain 3-ketoacyl-CoA thiolase & LCTHIO & NM_213966.1 & 2.497 \\
\hline Progesterone receptor membrane component 1 & PGRMC1 & NM_213911.1 & 2.48 \\
\hline Cyclin B2 & CCNB2 & CK451027 & 2.479 \\
\hline Metallothionein & MT1A & NM_001001266.1 & 2.478 \\
\hline Sulfotransferase family, cytosolic, $1 \mathrm{~A}$, phenol-preferring, member 1 & SULT1A1 & NM_213765.1 & 2.47 \\
\hline Lectin, galactoside-binding, soluble, 8 & LGALS8 & $\mathrm{BF} 080287$ & 2.461 \\
\hline Annexin A1 & ANXA1 & CO944050 & 2.46 \\
\hline Solute carrier family 26 , member 11 & SLC26A11 & CK461723 & 2.44 \\
\hline Epoxide hydrolase & EPHX1 & NM_214355.1 & 2.435 \\
\hline P450 oxidoreductase & POR & L33893.1 & 2.424 \\
\hline Propionyl Coenzyme A carboxylase, beta polypeptide & PCCB & NM_213901.1 & 2.423 \\
\hline DAZ associated protein 2 & DAZAP2 & BP169027 & 2.423 \\
\hline IgG heavy chain & LOC396781 & NM_213828.1 & 2.422 \\
\hline Chemokine ligand 9 & CXCL9 & BX914993 & 2.422 \\
\hline Scavenger receptor class $\mathrm{B}$, member 1 & SCARB1 & NM_213967.1 & 2.415 \\
\hline Hyaluronan synthase 3 & HAS3 & NM_001001268.1 & 2.41 \\
\hline DBF4 homolog & DBF4 & CF79 6296 & 2.407 \\
\hline Fatty acid binding protein 4 , adipocyte & FABP4 & AU059657 & 2.403 \\
\hline Clathrin, light chain & CLTA & BQ600136 & 2.396 \\
\hline $\mathrm{BH} 3$ interacting domain death agonist & BID & BX923313 & 2.394 \\
\hline Soluble epoxide hydrolase & LOC414425 & NM_001001641.1 & 2.39 \\
\hline Branched chain keto acid dehydrogenase E1, alpha polypeptide & BCKDHA & CF792961 & 2.389 \\
\hline Ubiquitin-conjugating enzyme $\mathrm{E} 2, \mathrm{~J} 1$ & UBE2J1 & CF790105 & 2.384 \\
\hline Non-histone protein HMG2 & HMGB2 & NM_214063.1 & 2.384 \\
\hline Goosecoid protein & GCS & Y $17 \overline{7} 18.1$ & 2.382 \\
\hline D-aspartate oxidase & DDO & CO942555 & 2.381 \\
\hline Sterol-C4-methyl oxidase-like & SC4MOL & NM_213752.1 & 2.37 \\
\hline MHC class II, DQ alpha & SBAB-591C4.5 & AY285927.1 & 2.364 \\
\hline Lactate dehydrogenase $\mathrm{B}$ & LDHB & U07180.1 & 2.358 \\
\hline Hypothetical protein LOC100153293 & LOC100153293 & BI184480 & 2.356 \\
\hline Granzyme H & GZMH & BX923569 & 2.355 \\
\hline Protein S (alpha) & PROS1 & CN154806 & 2.35 \\
\hline CD59 molecule, complement regulatory protein & CD59 & NM_214170.1 & 2.349 \\
\hline Thyroid hormone receptor beta 1 & C-ERBA-B1 & BX668616 & 2.349 \\
\hline Heme binding protein & LOC414409 & CN159822 & 2.348 \\
\hline Transmembrane BAX inhibitor motif containing 6 & TMBIM6 & CK451891 & 2.336 \\
\hline $\mathrm{Rh}$ protein & $\mathrm{RH}$ & NM_214378.1 & 2.335 \\
\hline Glutathione peroxidase 4 & GPX4 & BI183078 & 2.327 \\
\hline Malate dehydrogenase 1, NAD & MDH1 & NM_213874.1 & 2.326 \\
\hline Lysosomal 9kDa H+ transporting ATPase V0 subunit e & LOC733646 & CB472326 & 2.322 \\
\hline Thioltransferase & GLRX1 & NM 214233.1 & 2.319 \\
\hline Sirtuin 3 & SIRT3 & CF365373 & 2.316 \\
\hline Nitrogen fixation 1-like protein & LOC100156145 & CF360660 & 2.313 \\
\hline
\end{tabular}

Continued next on the page 


\begin{tabular}{|c|c|c|c|}
\hline Gene title & Gene symbol & Representative public ID & Ratio \\
\hline CCAAT/enhancer binding protein, alpha & CEBPA & AF103944.1 & 2.313 \\
\hline Superoxide dismutase 1 , soluble & SOD1 & CO992469 & 2.296 \\
\hline Ring finger protein 114 & RNF114 & CO939849 & 2.296 \\
\hline Cyclin B & CCNB1 & BX671487 & 2.271 \\
\hline Citrate synthase & $\mathrm{CS}$ & C94952 & 2.261 \\
\hline FK506 binding protein 7 & FKBP7 & CN153356 & 2.26 \\
\hline Six transmembrane epithelial antigen of the prostate 1 & STEAP1 & NM_214305.1 & 2.252 \\
\hline Phosphate regulating endopeptidase homolog, X-linked & PHEX & AJ316616.1 & 2.247 \\
\hline Cytochrome P450, family 39 , subfamily A, polypeptide 1 & CYP39A1 & CN154029 & 2.236 \\
\hline Neuronatin & NNAT & CK466245 & 2.234 \\
\hline Myosin VI & MYO6 & NM_214021.1 & 2.226 \\
\hline Inhibitor of DNA binding 2 & ID2 & 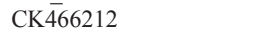 & 2.226 \\
\hline Caspase 8 , apoptosis-related cysteine peptidase & CASP8 & AJ663595 & 2.225 \\
\hline Fc fragment of IgG, low affinity IIIb, receptor & FCGR3B & $\mathrm{AF} 372455.1$ & 2.223 \\
\hline Hydroxysteroid (17-beta) dehydrogenase 4 & HSD17B4 & NM_214306.1 & 2.222 \\
\hline Proteoglycan 1 precursor-like & LOC100049692 & CK464602 & 2.203 \\
\hline NADPH oxidase heavy chain subunit & GP91-PHOX & NM_214043.1 & 2.195 \\
\hline B-cell translocation gene 1, anti-proliferative & BTG1 & CB $\overline{48} 1644$ & 2.193 \\
\hline Heme oxygenase 1 & HMOX1 & X60677.1 & 2.192 \\
\hline Glycoprotein, alpha-galactosyltransferase 1 & GGTA1 & L36535.1 & 2.191 \\
\hline Fatty acid binding protein 5 & FABP5 & BI400074 & 2.188 \\
\hline Caveolin 2 & CAV2 & BF191227 & 2.188 \\
\hline Cytochrome P450 2A19 & CYP2A19 & AY280866.1 & 2.182 \\
\hline Insulin-like growth factor binding protein 3 & IGFBP3 & AJ657291 & 2.181 \\
\hline Mitogen-activated protein kinase-activated protein kinase 5 & MAPKAPK5 & BI400519 & 2.177 \\
\hline Man9-mannosidase & MAN1A & NM_213885.1 & 2.165 \\
\hline Interleukin 1 receptor antagonist & IL1RN & $\mathrm{BF} 441608$ & 2.165 \\
\hline $\mathrm{H} 2 \mathrm{~A}$ histone family, member $\mathrm{Z}$ & $\mathrm{H} 2 \mathrm{AFZ}$ & CN154655 & 2.163 \\
\hline Acyl-CoA synthetase long-chain family member 1 & ACSL1 & BI118904 & 2.161 \\
\hline Eukaryotic translation elongation factor 1 alpha 1 & EEF1A1 & CO994537 & 2.159 \\
\hline Protein kinase inhibitor gamma & PKIG & NM_214371.1 & 2.146 \\
\hline Protein kinase $\mathrm{C}$ theta & LOC100152637 & $\mathrm{CN} 163635$ & 2.134 \\
\hline Integrin, beta 2 & ITGB2 & NM_213908.1 & 2.127 \\
\hline CD74 antigen & CD74 & CO994913 & 2.126 \\
\hline Solute carrier family 35 , member A3 & SLC35A3 & CK462997 & 2.118 \\
\hline Uteroferrin & UF & NM_214209.1 & 2.111 \\
\hline ST8 alpha-N-acetyl-neuraminide alpha-2,8-sialyltransferase 4 & ST8SIA4 & BF712001 & 2.105 \\
\hline Aldehyde reductase & ALR1 & NM_213890.1 & 2.098 \\
\hline Cellular FLICE-like inhibitory protein & C-FLIP & AY533020.1 & 2.089 \\
\hline Isocitrate dehydrogenase $3(\mathrm{NAD}+)$ beta & IDH3B & BX667411 & 2.078 \\
\hline Fibrinogen-like 2 & FGL2 & BP433439 & 2.069 \\
\hline Phosphoenolpyruvate carboxykinase 2 & PCK2 & CF180618 & 2.067 \\
\hline Peroxisomal D3,D2-enoyl-CoA isomerase & PECI & $\mathrm{CN} 160253$ & 2.065 \\
\hline Platelet/endothelial cell adhesion molecule & PECAM1 & NM_213907.1 & 2.061 \\
\hline Hypothetical protein LOC 100152540 & LOC100152540 & $\mathrm{CN} 164967$ & 2.055 \\
\hline Cyclin-dependent kinase 5 & LOC733700 & CF175515 & 2.054 \\
\hline HUS1 checkpoint homolog & HUS1 & CO946905 & 2.051 \\
\hline Spermidine/spermine N1-acetyltransferase 1 & SAT1 & NM_214358.1 & 2.048 \\
\hline Sphingosine-1-phosphate receptor 5 & S1PR5 & CF175881 & 2.044 \\
\hline Peroxiredoxin 6 & PRDX6 & NM_214408.1 & 2.043 \\
\hline Interferon, gamma-inducible protein 30 & IFI30 & CK 456242 & 2.041 \\
\hline Polo-like kinase 2 & PLK2 & CN159550 & 2.04 \\
\hline Ig gamma $2 \mathrm{~b}$ chain constant region & IGG2B & M81771.1 & 2.039 \\
\hline RAD18 homolog & RAD18 & CK461304 & 2.038 \\
\hline Hypothetical protein LOC 100153935 & LOC100153935 & NM 214005.1 & 2.027 \\
\hline Hypothetical protein LOC 100158166 & LOC100158166 & $\mathrm{BX} 671182$ & 2.02 \\
\hline Notch homolog 4 & SBAB-649D6.4 & CF360567 & 2.018 \\
\hline $\begin{array}{l}\mathrm{Cbp} / \mathrm{p} 300 \text {-interacting transactivator, with } \\
\text { Glu/Asp-rich carboxy-terminal domain, } 1\end{array}$ & CITED1 & BI183561 & 2.014 \\
\hline Spermidine/spermine N1-acetyltransferase family member 2 & SAT2 & CN162887 & 2.012 \\
\hline Galactose mutarotase & GALM & NM 214406.1 & 2.004 \\
\hline UDP-Gal:betaGlcNAc beta 1,4- galactosyltransferase, polypeptide 4 & B4GALT4 & CO956759 & 2.002 \\
\hline
\end{tabular}


Table 3. Highly expressed genes in intramuscular adipose tissue.

\begin{tabular}{|c|c|c|c|}
\hline Gene title & Gene symbol & Representative public ID & Ratio \\
\hline Uroplakin 3 & UPK3A & CK452028 & 0.5 \\
\hline Prepro-beta-defensin 1 & PBD-1 & NM_213838.1 & 0.497 \\
\hline Sorbin polypeptide & LOC396719 & AF396456.1 & 0.497 \\
\hline Cytochrome P450, family 7 , subfamily B, polypeptide 1 & CYP7B1 & CK455462 & 0.496 \\
\hline Carboxypeptidase E & $\mathrm{CPE}$ & CD571929 & 0.495 \\
\hline Calpastatin & CAST & AJ583408.1 & 0.493 \\
\hline Growth factor receptor-bound protein 10 & GRB10 & CF795733 & 0.491 \\
\hline CD9 molecule & CD9 & NM_214006.1 & 0.491 \\
\hline Glycoprotein hormones, alpha polypeptide & CGA & NM_214446.1 & 0.488 \\
\hline Sarcoglycan, gamma & SGCG & CK $\overline{45} 6888$ & 0.484 \\
\hline Integrin, beta 3 & ITGB3 & NM_214002.1 & 0.482 \\
\hline Thy-1 cell surface antigen & THY1 & $\mathrm{BX} \overline{6} 76685$ & 0.481 \\
\hline Thrombomodulin & THBD & BX676135 & 0.475 \\
\hline NADH dehydrogenase 1 , subcomplex unknown, 1, $6 \mathrm{kDa}$ & NDUFC1 & CK460082 & 0.474 \\
\hline Insulin-like growth factor binding protein 5 & IGFBP5 & NM_214099.1 & 0.474 \\
\hline Cyclin D2 & CCND2 & NM_214088.1 & 0.469 \\
\hline Follistatin & FST & NM_001003662.1 & 0.464 \\
\hline Calcium/calmodulin-dependent protein kinase II gamma & CAMK2G & U72972.1 & 0.463 \\
\hline NDRG2 & LOC780431 & BI182567 & 0.462 \\
\hline Complement component 7 & $\mathrm{C} 7$ & CO949473 & 0.462 \\
\hline Heat shock $105 \mathrm{kDa} / 110 \mathrm{kDa}$ protein 1 & HSPH1 & CO993113 & 0.458 \\
\hline Odd homeobox 1 protein & OB1 & NM_213792.1 & 0.447 \\
\hline Insulin-like growth factor 2 & IGF2 & NM_213883.1 & 0.446 \\
\hline Myocyte enhancer factor $2 \mathrm{~A}$ & MEF2A & BX917896 & 0.445 \\
\hline Glutathione peroxidase 2 & GPX2 & CF365816 & 0.439 \\
\hline Thrombospondin 1 & THBS1 & BQ601960 & 0.438 \\
\hline Biglycan & BGN & BF193177 & 0.433 \\
\hline Protein phosphatase 1 , regulatory subunit $12 \mathrm{~A}$ & PPP1R12A & BI183395 & 0.431 \\
\hline EGF-like-domain, multiple 8 & SBAB-649D6.3 & BE232302 & 0.429 \\
\hline Beta-defensin 2 & PBD-2 & NM_214442.1 & 0.424 \\
\hline Splicing factor, arginine/serine-rich 11 & LOC733656 & CK $\overline{46} 4903$ & 0.42 \\
\hline Glyceraldehyde-3-phosphate dehydrogenase & GAPDH & AF017079.1 & 0.415 \\
\hline LIM and cysteine-rich domains 1 & LMCD1 & CA779262 & 0.412 \\
\hline Inter-alpha inhibitor $\mathrm{H} 4$ & ITIH4 & NM_001001537.1 & 0.412 \\
\hline Bone morphogenetic protein receptor, type IB & BMPR1B & CO950299 & 0.412 \\
\hline ATG4 autophagy related 4 homolog D & ATG4D & CK453932 & 0.411 \\
\hline $\begin{array}{l}\text { Inhibitor of kappa light polypeptide gene enhancer in } \\
\text { B-cells, kinase gamma }\end{array}$ & IKBKG & BX925233 & 0.404 \\
\hline P311 protein & P311 & BQ598577 & 0.4 \\
\hline Activating transcription factor 4 & ATF4 & CF792678 & 0.397 \\
\hline Discoidin domain receptor tyrosine kinase 1 & DDR1 & CK457958 & 0.396 \\
\hline CD209 molecule & CD209 & BI399887 & 0.391 \\
\hline Complement component 3 & $\mathrm{C} 3$ & NM_214009.1 & 0.379 \\
\hline Cofilin 2 & CFL2 & BM0̄03222 & 0.374 \\
\hline Neuropeptide Y receptor Y1 & NPY1R & NM_214288.1 & 0.374 \\
\hline Prostamide/PG F synthase & LOC100134955 & CF179637 & 0.373 \\
\hline TIMP metallopeptidase inhibitor 1 & TIMP1 & NM_213857.1 & 0.368 \\
\hline Fibronectin & FN1 & BF709509 & 0.367 \\
\hline Vascular smooth muscle alpha-actin & ACT-4 & BX670904 & 0.366 \\
\hline Tenascin C & $\mathrm{TNC}$ & NM_214230.1 & 0.364 \\
\hline Nebulin-related anchoring protein & NRAP & CK459919 & 0.352 \\
\hline Insulin-like growth factor binding protein 2 & IGFBP2 & NM_214003.1 & 0.347 \\
\hline Chemokine ligand 2 & CXCL2 & BF078671 & 0.345 \\
\hline Isocitrate dehydrogenase $2\left(\mathrm{NADP}^{+}\right)$, mitochondrial & IDH2 & CN159777 & 0.344 \\
\hline TrkB protein & TRKB & BP171877 & 0.339 \\
\hline PROCR-like & LOC654289 & BX922318 & 0.339 \\
\hline Protein kinase inhibitor alpha & PKIA & NM_214204.1 & 0.338 \\
\hline Carnitine palmitoyltransferase $1 \mathrm{~B}$ & CPT1B & AY 181062.1 & 0.338 \\
\hline Collagen, type VI, alpha 1 & COL6A1 & CN162503 & 0.336 \\
\hline Serpin peptidase inhibitor, clade E, member 1 & SERPINE1 & NM_213910.1 & 0.335 \\
\hline Nicotinamide phosphoribosyltransferase & NAMPT & BX666697 & 0.33 \\
\hline Destrin & DSTN & D90053.1 & 0.327 \\
\hline
\end{tabular}

Continued next on the page 


\begin{tabular}{|c|c|c|c|}
\hline Gene title & Gene symbol & Representative public ID & Ratio \\
\hline Cadherin 1, type 1, E-cadherin & $\mathrm{CDH} 1$ & BQ604786 & 0.324 \\
\hline Stanniocalcin 1 & STC1 & BI400766 & 0.323 \\
\hline Calcineurin A protein & LOC396603 & BI118300 & 0.318 \\
\hline Phospholamban & PLN & NM_214213.1 & 0.316 \\
\hline Parathyroid hormone-like hormone & PTHLH & NM_213916.1 & 0.315 \\
\hline Calcium/calmodulin-dependent protein kinase II delta & CAMK2D & NM_214381.1 & 0.305 \\
\hline Glucose phosphate isomerase & GPI & NM_214330.1 & 0.296 \\
\hline TEA domain family member 4 & TEAD4 & CF17̄6015 & 0.293 \\
\hline Heat shock protein 70.2 & SBAB-707F 1.4 & NM 213766.1 & 0.289 \\
\hline Sarcoplasmic/endoplasmic-reticulum $\mathrm{Ca}(2+)$ pump gene 2 & SERCA2 & $\mathrm{X} 15073.1$ & 0.284 \\
\hline Claudin 7 & CLDN7 & CK450245 & 0.272 \\
\hline Dickkopf homolog 3 & DKK3 & CO949346 & 0.267 \\
\hline Mitogen-activated protein kinase 12 & MAPK12 & BI360380 & 0.265 \\
\hline Zinc finger, AN1-type domain 5 & ZFAND5 & CN160422 & 0.264 \\
\hline Collagen, type I, alpha 1 & COL1A1 & AF201723.1 & 0.263 \\
\hline CD55 molecule, decay accelerating factor for complement & CD55 & NM_213815.1 & 0.256 \\
\hline Maternally expressed 3 & MEG3 & CK451038 & 0.255 \\
\hline Stearoyl-CoA desaturase 5 & SCD5 & CN153640 & 0.251 \\
\hline Filamin A, alpha & FLNA & CN166104 & 0.243 \\
\hline Heat shock protein 70 & HSP70 & X68213.1 & 0.243 \\
\hline Monoamine oxidase B & MAOB & NM_001001864.1 & 0.241 \\
\hline Triosephosphate isomerase 1 & TPI1 & CN160134 & 0.23 \\
\hline Transferrin & $\mathrm{TF}$ & BX919174 & 0.23 \\
\hline Chloride intracellular channel 5 & CLIC5 & BX666230 & 0.229 \\
\hline Solute carrier family 16 , member 3 & SLC16A3 & BX676033 & 0.226 \\
\hline Tenascin-X & SBAB-514B12.2 & CF359969 & 0.221 \\
\hline Feline leukemia virus subgroup A receptor & LOC100155620 & BE014165 & 0.22 \\
\hline Fibromodulin & FMOD & CN163410 & 0.215 \\
\hline Smooth muscle protein 22 -alpha & SM22A & CK466398 & 0.213 \\
\hline Calcium channel, voltage-dependent, alpha $2 /$ delta subunit 1 & CACNA2D1 & NM_214183.1 & 0.208 \\
\hline ATPase, $\mathrm{Na}^{+} / \mathrm{K}^{+}$transporting, beta 1 polypeptide & ATP1B1 & CO9̄50644 & 0.206 \\
\hline Dnaj homolog, subfamily A, member 4 & DNAJA4 & NM_214339.1 & 0.199 \\
\hline Neuron-derived orphan receptor-1 alfa & NOR-1 & NM_214247.1 & 0.197 \\
\hline $\mathrm{C} 1 \mathrm{q}$ and tumor necrosis factor related protein 3 & C1QTNF3 & BQ599486 & 0.194 \\
\hline Phospholipase C, delta 4 & PLCD4 & NM_214052.1 & 0.192 \\
\hline Myosin regulatory light polypeptide 9 & MYL9 & CK $\overline{455118}$ & 0.189 \\
\hline Transforming growth factor, beta 3 & TGFB3 & NM_214198.1 & 0.187 \\
\hline Protein phosphatase 1 , regulatory subunit $14 \mathrm{~A}$ & PPP1R14A & NM 214337.1 & 0.184 \\
\hline Cardiac muscle alpha actin 1 & ACTC1 & CO939491 & 0.169 \\
\hline Pyruvate kinase, muscle & PKM2 & CN166623 & 0.168 \\
\hline Transducer of ERBB2, 1 & TOB1 & BQ598689 & 0.165 \\
\hline ATPase inhibitory factor 1 & ATPIF1 & AJ 604725 & 0.165 \\
\hline Integrin beta 1 binding protein 2 & ITGB1BP2 & BX924523 & 0.154 \\
\hline Keratin 8 & KRT8 & BX667006 & 0.153 \\
\hline Phosphoglucomutase 1 & PGM1 & AF091607.1 & 0.15 \\
\hline Four and a half LIM domains 3 & FHL3 & NM_213946.1 & 0.149 \\
\hline Pleiotrophic factor beta & PTF-BETA & D89546.1 & 0.148 \\
\hline Chemokine ligand 21 & CCL21 & AY312067.1 & 0.142 \\
\hline $\begin{array}{l}\text { Cartilage intermediate layer protein, } \\
\text { nucleotide pyrophosphohydrolase }\end{array}$ & CILP & U83114.1 & 0.141 \\
\hline Collagen, type VI, alpha 3 & COL6A3 & BI182335 & 0.136 \\
\hline Calponin 1, basic, smooth muscle & CNN1 & NM_213878.1 & 0.129 \\
\hline Collagen, type VIII, alpha 1 & COL8A1 & AF05 4891.1 & 0.124 \\
\hline Tropomyosin 2 & TPM2 & CF180239 & 0.122 \\
\hline Proteolipid protein 1 & PLP1 & BQ601666 & 0.122 \\
\hline Amylase, alpha $2 \mathrm{~B}$ & AMY2B & NM_214195.1 & 0.116 \\
\hline Tumor necrosis factor receptor superfamily, member $12 \mathrm{~A}$ & TNFRSF12A & BF710490 & 0.114 \\
\hline Bridging integrator 1 & BIN1 & CN162285 & 0.098 \\
\hline Fat-inducing transcript 1 & FIT1 & CF180497 & 0.09 \\
\hline Unc-45 homolog B & UNC45B & CN069994 & 0.087 \\
\hline Reticulon 2 & RTN2 & CF179996 & 0.077 \\
\hline Na,K-ATPase alpha 2 subunit & LOC396828 & BX673191 & 0.077 \\
\hline
\end{tabular}


Table 3. Continued.

\begin{tabular}{|c|c|c|c|}
\hline Gene title & Gene symbol & Representative public ID & Ratio \\
\hline Oculocutaneous albinism II & OCA2 & NM_214094.1 & 0.063 \\
\hline Myogenic factor 6 & MYF6 & AY188502.1 & 0.063 \\
\hline ADP-ribosyltransferase 3 & ART3 & AJ291435.1 & 0.051 \\
\hline Titin & TTN & CF359670 & 0.047 \\
\hline Calpain 3 & CAPN3 & AF148955.1 & 0.045 \\
\hline Tropomyosin 1 & TPM1 & CN165926 & 0.042 \\
\hline Adenylosuccinate synthase like 1 & ADSSL1 & CK456903 & 0.038 \\
\hline Titin-cap & TCAP & BM190107 & 0.032 \\
\hline Troponin C & TNNC1 & CK449959 & 0.032 \\
\hline Phosphofructokinase, muscle & PFKM & CK466479 & 0.028 \\
\hline Muscle-specific intermediate filament desmin & LOC396725 & NM_001001535.1 & 0.026 \\
\hline $\mathrm{COX} 8 \mathrm{H}$ protein & $\mathrm{COX} 8 \mathrm{H}$ & BX921027 & 0.024 \\
\hline Myosin, heavy chain 7 , cardiac muscle, beta & MYH7 & U75316.1 & 0.019 \\
\hline Epidermal growth factor & EGF & NM_214020.1 & 0.018 \\
\hline Troponin I & TNNI1 & NM_213912.1 & 0.015 \\
\hline Skeletal alpha actin & LOC100154254 & BM1̄-00097 & 0.013 \\
\hline Myosin, light chain 1, alkali; skeletal, fast & MYL1 & NM_214374.1 & 0.011 \\
\hline Calsarcin 1 & LOC733663 & CF17̄8743 & 0.011 \\
\hline Popeye domain containing 3 & POPDC3 & CF180347 & 0.011 \\
\hline Myosin light chain, phosphorylatable, fast skeletal muscle & MYLPF & AJ604745 & 0.007 \\
\hline Myosin, heavy chain 4 , skeletal muscle & MYH4 & AB025260.1 & 0.007 \\
\hline Xin actin-binding repeat containing 1 & XIRP1 & BI596265 & 0.007 \\
\hline Ryanodine receptor 1 & RYR1 & M91451.1 & 0.007 \\
\hline Beta actin & LOC396797 & L20459 & 0.007 \\
\hline Troponin C type 2 & TNNC2 & NM_001001862.1 & 0.006 \\
\hline Myosin binding protein $\mathrm{H}$ & МYBPH & BX $\overline{6} 76336$ & 0.006 \\
\hline Creatine kinase, muscle & CKM & AF165173.1 & 0.006 \\
\hline $\begin{array}{l}\text { Peroxisome proliferator activated receptor gamma, } \\
\text { coactivator } 1 \text { alpha }\end{array}$ & PPARGC-1 & AB106108.1 & 0.006 \\
\hline Myosin light chain $2 \mathrm{~V}$ & MLC2V & NM_213791.1 & 0.006 \\
\hline Creatine kinase, mitochondrial 2 & CKMT2 & BX $\overline{6} 67443$ & 0.006 \\
\hline Xin actin-binding repeat containing 2 & XIRP2 & NM_214396.1 & 0.005 \\
\hline Sarcolipin & SLN & BX676059 & 0.005 \\
\hline Phosphorylase, glycogen, muscle & PYGM & CF179951 & 0.005 \\
\hline Enolase 3 & ENO3 & AJ301332 & 0.005 \\
\hline Myoglobin & MB & NM_214236.1 & 0.005 \\
\hline Cardiac ankyrin repeat protein & CARP & NM_213922.1 & 0.005 \\
\hline Actin-binding Rho activating protein & ABRA & BX $\overline{6} 67447$ & 0.005 \\
\hline Troponin T type 3 & TNNT3 & AB176599.1 & 0.004 \\
\hline Phosphoglycerate mutase 2 & PGAM2 & BX667605 & 0.004 \\
\hline Troponin I & TNNI2 & AJ604638 & 0.004 \\
\hline Alpha-actinin-2-associated LIM protein & LIM & NM_001001637.1 & 0.004 \\
\hline Myozenin 1 & MYOZ1 & $\mathrm{BX} \overline{6} 75224$ & 0.003 \\
\hline Troponin T type 1 & TNNT1 & AB118908.1 & 0.003 \\
\hline Small muscle protein, $\mathrm{X}$-linked & SMPX & BX664815 & 0.002 \\
\hline Myotilin & MYOT & BM190434 & 0.002 \\
\hline Adenosine monophosphate deaminase 1 & AMPD1 & AJ604865 & 0.002 \\
\hline
\end{tabular}

Table 4. Gene Ontology results of differentially expressed probes of subcutaneous (s.c.) and intramuscular (i.m.) (Figure $2 \mathrm{~B}$ ) adipose tissues.

\begin{tabular}{lcr}
\hline Classification & \multicolumn{2}{c}{ Content (\%) } \\
\cline { 2 - 3 } & s.c. adipose tissue & i.m. adipose tissue \\
\hline Biological process & 49.25 & 49.16 \\
Molecular function & 35.15 & 31.76 \\
Cellular component & 14.10 & 18.07 \\
Other items & 1.50 & 1.01 \\
\hline
\end{tabular}




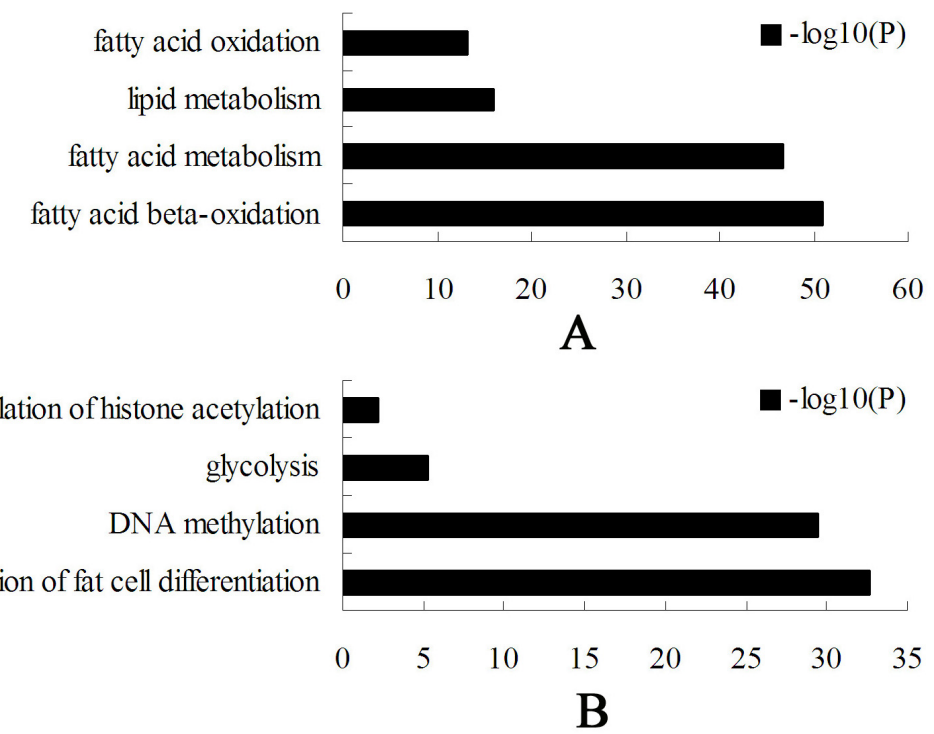

Figure 2. Biological process analyzed of genes that changed two-fold $\geq 2$ folds in subcutaneous (A) and intramuscular adipose tissue $(\mathbf{B})$ by Gene Ontology analysis ( $\mathrm{P}$ values $<0.05$ ). negative regulation of fat cell differentiation

A Insulin signaling pathway
Jak-STAT signaling pathway
Adipocytokine signaling pathway
Glycerolipid metabolism
Fatty acid elongation in mitochondria
Fatty acid metabolism
Glycolysis/Gluconeogenesis Glycolsis Gluconegenesis $\log 10(\mathrm{P})$

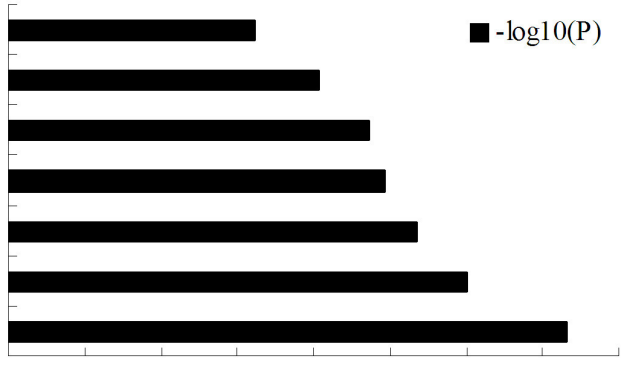

$\begin{array}{lllllllll}0 & 0.5 & 1 & 1.5 & 2 & 2.5 & 3 & 3.5 & 4\end{array}$

B
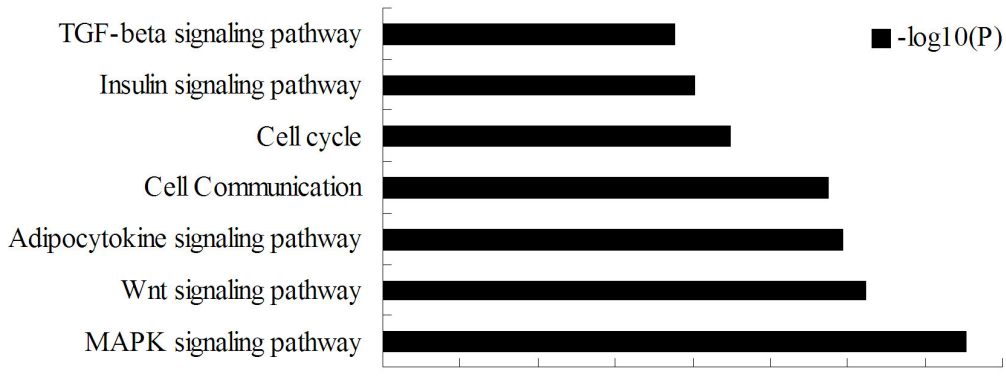

$\begin{array}{lllllllll}0 & 0.5 & 1 & 1.5 & 2 & 2.5 & 3 & 3.5 & 4\end{array}$

Figure 3. Significant pathways analyzed of genes that changed two-fold $\geq 2$ folds in subcutaneous (A) and intramuscular adipose tissue $(\mathbf{B})$ by KEGG analysis ( $\mathrm{P}$ values $<0.05)$.

Genetics and Molecular Research 12 (4): 5085-5101 (2013)

CFUNPEC-RP www.funpecrp.com.br 


\section{RT-PCR}

In order to validate the microarray chips results, 13 randomly selected genes were analyzed using RT-PCR. As Figure 4A showed, FAS, LEP, ADIPOQ, PPAR- $\gamma$, intramuscular FABP5, FABP4, and LPL were more highly expressed in s.c. adipose tissue. On the contrary, GPI, CCND2, IGF2, NOR-1, TPI1, and TOB1 were more highly expressed in i.m. adipose tissue. The RT-PCR results were in accordance with the chips results (Figure 4B).
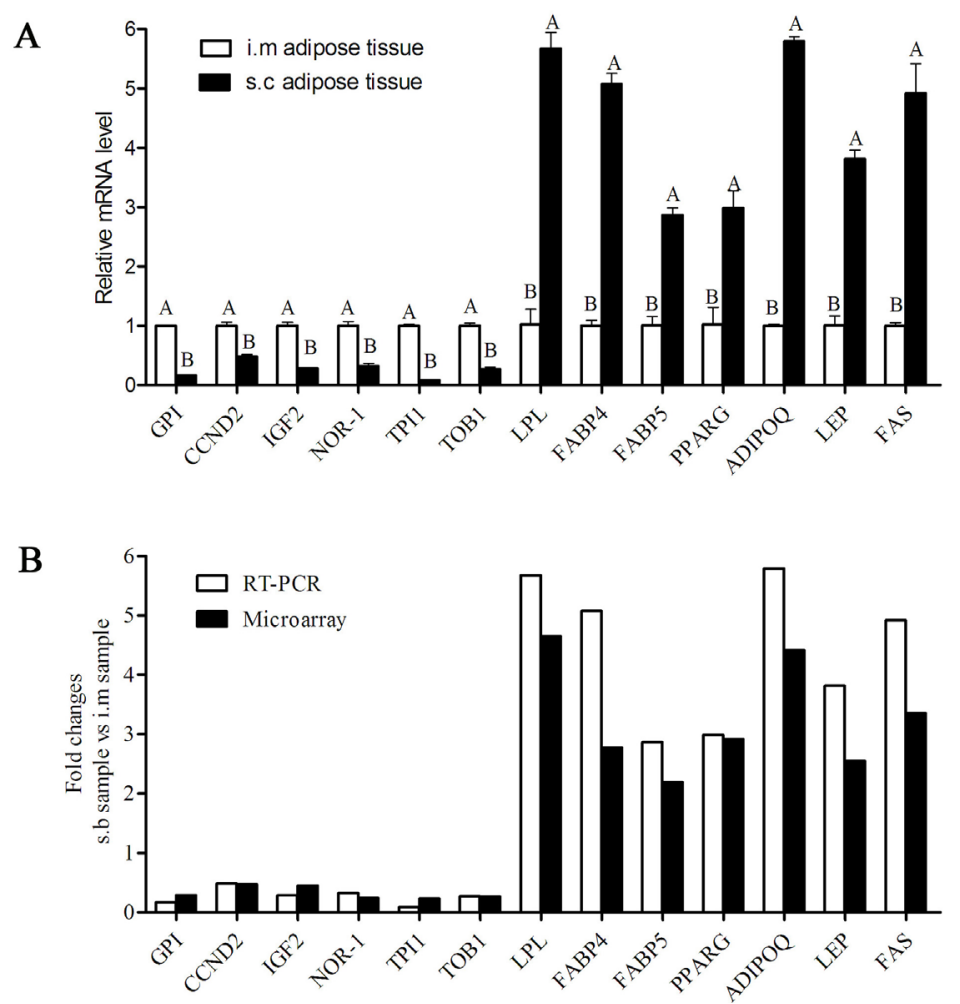

Figure 4. Microarry results conformed by RT-PCR. A. RT-PCR results of the genes selected. B. Comparison between RT-RCR and microarry results.

\section{DISCUSSION}

From the GO biological process analysis, we found that fatty acid oxidation, fatty acid $\beta$-oxidation, fatty acid metabolism, and lipid metabolism occurred in higher levels in s.c. adipose tissue. The KEGG results revealed that fatty acid elongation in mitochondria, fatty acid metabolism, and glycerolipid metabolism were significantly more highly expressed in s.c. adipose tissue. These results imply that s.c. adipose tissue has different abilities of lipid metabolism and fatty acid metabolism compared with i.m. adipose tissue.

LPL and FAS are the rate-limiting enzymes of triglyceride accumulation in adipose tissue (Weinstock et al., 1997; Ranganathan et al., 2006). FABP4 and FABP5, which are strongly 
associated with fat accumulation, are key mediators of lipid metabolism and intracellular transport (Gorbenko et al., 2006; Ma et al., 2010). Hormone-sensitive lipase (HSL), catalyzing the triglycerides and diglycerides to form glycerol and fatty acids, is a key enzyme in the lipolysis process (Haemmerle et al., 2002; Holm, 2003). FABP4 regulates metabolism by affecting the activities of HSL and PPAR- $\gamma$, and has a higher expression in the NIH 3T3-L1 induction process (Gorbenko et al., 2006). Apolipoprotein E (APOE), which can improve the content of free fatty acid and triglyceride in adipose tissue (Huang et al., 2006), had a 4.8-fold higher expression than that in i.m. adipose tissue. In this study, LPL, FAS, FABP4, FABP5, HSL, and APOE were more highly expressed in s.c. adipose tissue, which implied that s.c. adipose tissue has a stronger lipogenic and lipolytic capacity. This higher level of lipogenic metabolism in s.c. tissue was coincidence with a previous report, in that s.c. adipocytes exhibit stronger lipogenesis in the process of preadipocyte differentiation to mature adipocytes in neonatal pigs (Zhou et al., 2010), as well as in mature adipoctyes of 210-day female pigs (Gardan et al., 2006).

Enoyl coenzyme A hydratase 1 peroxisomal (ECH1) and 2,4-dienoyl CoA reductase 1 , mitochondrial (DECR1) are the rate-limiting enzymes in $\beta$-oxidation of fatty acid (CastroChavez et al., 2003). Our results revealed that the expression levels of HSL, ECH1, and DECR1 in s.c. adipose tissue were 3.24-, 3.321-, and 2.875-fold of those in i.m. adipose tissue, respectively. In the s.c. depot, ADIPOQ and adiponectin receptor 2 (ADIPOR2) are both highly expressed. ADIPOR 2 positively regulates energy dissipation and fatty acid oxidation by activation of the PPAR- $\alpha$ pathway (Yamauchi et al., 2007). Thus, s.c. adipose tissue was more sensitive to adiponectin, and had a stronger ability of energy dissipation. Therefore, the high expression of ECH1, DECR1, ADIPOQ, and ADIPOR2 may imply that the s.c. adipose tissue also has a stronger capacity of fatty acid $\beta$-oxidation compared with i.m. adipose tissue. Adipose differentiationrelated protein (ADRP) increases the uptake of long-chain fatty acids (Gao and Serrero, 2000) and its expression can increase the accumulation of neural lipid droplets (Londos et al., 1999). Our results also showed a high level of ADRP in s.c. adipose tissue. These implicate that s.c. adipose tissue has higher abilities for fatty acid uptake compared with i.m. adipose tissue.

In summary, the s.c. adipose tissue had a stronger ability for lipid metabolism and fatty acid metabolism than i.m. adipose tissue. Besides the biological process differences in different fat depots, angiopoietin-like-4 (ANGPTL4), neuronatin (NNAT), neuron-derived orphan receptor-1 alfa (NOR-1), and chloride intracellular channel 5 (CLIC5) may also participate in the metabolism differences between s.c. and i.m. adipose tissues.

ANGPTL4 and NNAT were highly expressed in s.c. adipose tissue compared with i.m. adipose tissue. ANGPTL4 is strongly up-regulated in the differentiation of 3T3-L1, and regulates the deposition of lipid and energy homeostasis (Lei et al., 2011) by suppressing fat accumulation (Mandard et al., 2006) and advancing fatty acids oxidation (Backhed et al., 2007). Compared with i.m. adipose tissue, the expression level of ANGPTL4 in s.c. adipose tissue was about 3.4-fold higher. The imprinted gene NNAT can promote adipogenesis in 3T3L1 cells by enhancing the phosphorylation of cyclic AMP-response element-binding protein (Suh et al., 2005). NNAT expression is also influenced by leptin as a hypothalamic target (Vrang et al., 2010). The research of NNAT is mainly in the nervous system, and little about it in adipose tissue is known.

NOR-1 and CLIC5 were highly expressed in i.m. adipose tissue compared with s.c. adipose tissue. NOR-1, as a nuclear receptor of the unclear receptor 4A, regulates the metabolism of glucose and lipid in skeletal muscle, liver, and adipose tissues (van Tiel and de Vries, 
2012), and is a target of $\beta$-adrenergic signaling in skeletal muscle (Pearen et al., 2006). NOR-1 inhibits adipogenesis of 3T3-L1 or 3T3-F442A pre-adipocytes (Chao et al., 2008), and NOR-1 gene transcription is regulated by liver $X$ in adipocytes (Kumar et al., 2009). The specific function of CLIC5 is poorly understood (Bradford et al., 2010). Recent research found that CLIC5 had higher expression in lean-type pig than in obese-type pig, and was negatively related with i.m. fat content (Li et al., 2010). CLIC5 inhibits the differentiation of adipocytes and promotes the proliferation of 3T3-L1 (Li et al., 2010). NOR-1 and CLIC5 were significantly more highly expressed in i.m. adipose tissue. Therefore, ANGPTL4, NNAT, NOR-1, and CLIC5 can be candidate genes for the difference in lipid metabolism between s.c. and i.m. adipose tissues.

\section{ACKNOWLEDGMENTS}

Research supported by National Natural Science Foundation of China (\#31272423). This research was also supported by the Fundamental Research Funds for the Central Universities (\#KYZ201113).

\section{REFERENCES}

Backhed F, Manchester JK, Semenkovich CF and Gordon JI (2007). Mechanisms underlying the resistance to diet-induced obesity in germ-free mice. Proc. Natl. Acad. Sci. U. S. A. 104: 979-984.

Bradford EM, Miller ML, Prasad V, Nieman ML, et al. (2010). CLIC5 mutant mice are resistant to diet-induced obesity and exhibit gastric hemorrhaging and increased susceptibility to torpor. Am. J. Physiol. Regul. Integr. Comp. Physiol. 298: R1531-R1542.

Castro-Chavez F, Yechoor VK, Saha PK, Martinez-Botas J, et al. (2003). Coordinated upregulation of oxidative pathways and downregulation of lipid biosynthesis underlie obesity resistance in perilipin knockout mice: a microarray gene expression profile. Diabetes 52: 2666-2674.

Chao LC, Bensinger SJ, Villanueva CJ, Wroblewski K, et al. (2008). Inhibition of adipocyte differentiation by Nur77, Nurr1, and Nor1. Mol. Endocrinol. 22: 2596-2608.

Fernandez X, Monin G, Talmant A, Mourot J, et al. (1999). Influence of intramuscular fat content on the quality of pig meat - 1. Composition of the lipid fraction and sensory characteristics of m. longissimus lumborum. Meat Sci. 53: $59-65$.

Gao J, Ye H and Serrero G (2000). Stimulation of adipose differentiation related protein (ADRP) expression in adipocyte precursors by long-chain fatty acids. J. Cell Physiol. 182: 297-302.

Gardan D, Gondret F and Louveau I (2006). Lipid metabolism and secretory function of porcine intramuscular adipocytes compared with subcutaneous and perirenal adipocytes. Am. J. Physiol. Endocrinol. Metab. 291: E372-E380.

Gorbenko O, Filonenko V and Gout I (2006). Generation and characterization of monoclonal antibodies against FABP4. Hybridoma 25: 86-90.

Haemmerle G, Zimmermann R, Hayn M, Theussl C, et al. (2002). Hormone-sensitive lipase deficiency in mice causes diglyceride accumulation in adipose tissue, muscle, and testis. J. Biol. Chem. 277: 4806-4815.

Hausman GJ and Hausman DB (2006). Search for the preadipocyte progenitor cell. J. Clin. Invest. 116: 3103-3106.

Hermesch S, Luxford BG and Graser H-U (2000). Genetic parameters for lean meat yield, meat quality, reproduction and feed efficiency traits for Australian pigs. Livest. Prod. Sci. 65: 249-259.

Holm C (2003). Molecular mechanisms regulating hormone-sensitive lipase and lipolysis. Biochem. Soc. Trans. 31: 11201124.

Huang ZH, Reardon CA and Mazzone T (2006). Endogenous ApoE expression modulates adipocyte triglyceride content and turnover. Diabetes 55: 3394-3402.

Katz BZ, Zamir E, Bershadsky A, Kam Z, et al. (2000). Physical state of the extracellular matrix regulates the structure and molecular composition of cell-matrix adhesions. Mol. Biol. Cell 11: 1047-1060.

Kumar N, Wang H, Liu D and Collins S (2009). Liver X receptor is a regulator of orphan nuclear receptor NOR-1 gene transcription in adipocytes. Int. J. Obes. 33: 519-524.

Lei X, Shi F, Basu D, Huq A, et al. (2011). Proteolytic processing of angiopoietin-like protein 4 by proprotein convertases modulates its inhibitory effects on lipoprotein lipase activity. J. Biol. Chem. 286: 15747-15756. 
Li FN, Yin JD, Ni JJ, Liu L, et al. (2010). Chloride intracellular channel 5 modulates adipocyte accumulation in skeletal muscle by inhibiting preadipocyte differentiation. J. Cell Biochem. 110: 1013-1021.

Lo LL, McLaren DG, McKeith FK, Fernando RL, et al. (1992). Genetic analyses of growth, real-time ultrasound, carcass, and pork quality traits in Duroc and Landrace pigs: II. Heritabilities and correlations. J. Anim. Sci. 70: 2387-2396.

Londos C, Brasaemle DL, Schultz CJ, Segrest JP, et al. (1999). Perilipins, ADRP, and other proteins that associate with intracellular neutral lipid droplets in animal cells. Semin. Cell Dev. Biol. 10: 51-58.

Ma X, Ren X, Han P, Hu S, et al. (2010). SiRNA against Fabp5 induces 3T3-L1 cells apoptosis during adipocytic induction. Mol. Biol. Rep. 37: 4003-4011.

Mandard S, Zandbergen F, van Straten E, Wahli W, et al. (2006). The fasting-induced adipose factor/angiopoietin-like protein 4 is physically associated with lipoproteins and governs plasma lipid levels and adiposity. J. Biol. Chem. 281: 934-944.

Pearen MA, Ryall JG, Maxwell MA, Ohkura N, et al. (2006). The orphan nuclear receptor, NOR-1, is a target of betaadrenergic signaling in skeletal muscle. Endocrinology 147: 5217-5227.

Pickworth CL, Loerch SC, Velleman SG, Pate JL, et al. (2011). Adipogenic differentiation state-specific gene expression as related to bovine carcass adiposity. J. Anim. Sci. 89: 355-366.

Ranganathan G, Unal R, Pokrovskaya I, Yao-Borengasser A, et al. (2006). The lipogenic enzymes DGAT1, FAS, and LPL in adipose tissue: effects of obesity, insulin resistance, and TZD treatment. J. Lipid. Res. 47: 2444-2450.

Rebbapragada A, Benchabane H, Wrana JL, Celeste AJ, et al. (2003). Myostatin signals through a transforming growth factor beta-like signaling pathway to block adipogenesis. Mol. Cell Biol. 23: 7230-7242.

Suh YH, Kim WH, Moon C, Hong YH, et al. (2005). Ectopic expression of neuronatin potentiates adipogenesis through enhanced phosphorylation of cAMP-response element-binding protein in 3T3-L1 cells. Biochem. Biophys. Res. Commun. 337: 481-489.

Sun D, Zhu X, Qiao S, Fan S, et al. (2004). Effects of conjugated linoleic acid levels and feeding intervals on performance, carcass traits and fatty acid composition of finishing barrows. Arch. Anim. Nutr. 58: 277-286.

Suzuki K, Irie M, Kadowaki H, Shibata T, et al. (2005). Genetic parameter estimates of meat quality traits in Duroc pigs selected for average daily gain, longissimus muscle area, backfat thickness, and intramuscular fat content. J. Anim. Sci. 83: 2058-2065.

van Tiel CM and de Vries CJ (2012). NR4All in the vessel wall. J. Steroid Biochem. Mol. Biol. 130: 186-193.

Vohl MC, Sladek R, Robitaille J, Gurd S, et al. (2004). A survey of genes differentially expressed in subcutaneous and visceral adipose tissue in men. Obes. Res. 12: 1217-1222.

Vrang N, Meyre D, Froguel P, Jelsing J, et al. (2010). The imprinted gene neuronatin is regulated by metabolic status and associated with obesity. Obesity (Silver Spring) 18: 1289-1296.

Webb EC and O'Neill HA (2008). The animal fat paradox and meat quality. Meat Sci. 80: 28-36.

Weinstock PH, Levak-Frank S, Hudgins LC, Radner H, et al. (1997). Lipoprotein lipase controls fatty acid entry into adipose tissue, but fat mass is preserved by endogenous synthesis in mice deficient in adipose tissue lipoprotein lipase. Proc. Natl. Acad. Sci. U. S. A. 94: 10261-10266.

Yamauchi T, Nio Y, Maki T, Kobayashi M, et al. (2007). Targeted disruption of AdipoR1 and AdipoR2 causes abrogation of adiponectin binding and metabolic actions. Nat. Med. 13: 332-339.

Zhou G, Wang S, Wang Z, Zhu X, et al. (2010). Global comparison of gene expression profiles between intramuscular and subcutaneous adipocytes of neonatal landrace pig using microarray. Meat Sci. 86: 440-450. 